\title{
CSF Neurofilament Light Chain Concentrations Predict Outcome in Bacterial Meningitis
}

\author{
Nora Chekrouni, MD, Thijs M. van Soest, MD, Matthijs C. Brouwer, MD, PhD, Eline A.J. Willemse, MSc,
} Charlotte E. Teunissen, PhD, and Diederik van de Beek, MD, PhD

Neurol Neuroimmunol Neuroinflamm 2022;9:e1123. doi:10.1212/NXI.0000000000001123

\section{Abstract}

\section{Background and Objectives}

Neurofilament light chain (NfL) is a biomarker for neuroaxonal damage and has been found to be elevated proportionally to the degree of neuronal damage in neurologic diseases. The objective of this study was to determine the prognostic accuracy of NfL concentrations on unfavorable outcome in adults with community-acquired bacterial meningitis.

\section{Methods}

We measured NfL concentration CSF samples from a prospective cohort study of adults with community-acquired bacterial meningitis in The Netherlands and determined associations between NfL CSF concentrations, clinical characteristics, and outcome in multivariate analyses. We identified independent predictors of an unfavorable outcome (Glasgow Outcome Scale scores 1-4) by logistic regression.

\section{Results}

CSF NfL concentrations were evaluated in 429 episodes of 425 patients with community-acquired bacterial meningitis. The median age of 429 episodes was 62 years (interquartile range, 50-69 years). Of note, 290 of 422 (68\%) episodes presented with an altered mental status (Glasgow Coma Scale score $<14)$. Most common causative pathogens were Streptococcus pneumoniae (73\%), Neisseria meningitidis (7\%), and Listeria monocytogenes (5\%). The overall case fatality rate was 62 of 429 (15\%), and unfavorable outcome occurred in 57 (37\%) of 429 episodes. In multivariate analysis, predictors of unfavorable outcome were older age (OR 1.03, 95\% CI 1.01-1.05), cranial nerve palsy (OR 4, 95\% CI 1.6-10.3), high serum C-reactive protein concentration (OR 1.3, 95\% CI 1.01-1.05), and high CSF NfL concentration (OR 1.5, 95\% CI 1.07-2.00). CSF NfL concentrations were higher in patients presenting with focal cerebral deficits $(717 \mathrm{pg} / \mathrm{mL}[416-1,401]$ vs $412 \mathrm{pg} / \mathrm{mL}[278-731] ; p<0.001$ ). The area under the curve (AUC) for predicting unfavorable outcome in bacterial meningitis of CSF NfL concentration was 0.69 (95\% CI, 0.64-0.74).

\section{Discussion}

CSF NfL concentration is independently associated with unfavorable outcome in adults with community-acquired bacterial meningitis, suggesting that CSF NfL concentration may be a useful biomarker for prognostic assessment in bacterial meningitis.

\section{Classification of Evidence}

Can the level of NfL in CSF (the index test) predict unfavorable outcome in patients with bacterial meningitis, in a cohort of bacterial meningitis patients with a favorable and unfavorable outcome? This study provides Class II evidence that NfL level in CSF is a moderate predictor, with the AUC for predicting unfavorable outcome in bacterial meningitis being 0.69 (95\% CI, 0.64-0.74).

\author{
Correspondence \\ Dr. van de Beek \\ d.vandebeek@amsterdamumc.nl
}

\section{MORE ONLINE \\ (II) Class of Evidence}

Criteria for rating

therapeutic and diagnostic

studies

NPub.org/coe

From the Department of Neurology (N.C., T.M.S., M.C.B., D.B.), University of Amsterdam, Amsterdam Neuroscience, Amsterdam UMC, Meibergdreef; and Department of Clinical Chemistry (E.A.J.W., C.E.T.), Vrije Universiteit Amsterdam, Amsterdam Neuroscience, Neurochemistry Laboratory, Amsterdam UMC, De Boelelaan 1117, Amsterdam, The Netherlands.

Go to Neurology.org/NN for full disclosures. Funding information is provided at the end of the article.

The Article Processing Charge was funded by the authors.

This is an open access article distributed under the terms of the Creative Commons Attribution-NonCommercial-NoDerivatives License 4.0 (CC BY-NC-ND), which permits downloading and sharing the work provided it is properly cited. The work cannot be changed in any way or used commercially without permission from the journal. 


\section{Glossary}

ALS = amyotrophic lateral sclerosis; AUC = area under the curve; FTD = frontotemporal dementia; GCS = Glasgow Coma Scale; GOS = Glasgow Outcome Scale; IQR = interquartile range; $\mathbf{M S}=$ multiple sclerosis; $\mathbf{N f L}=$ neurofilament light chain.

Bacterial meningitis is a life-threatening disease associated with high mortality and morbidity and is predominantly caused by Streptococcus pneumoniae. ${ }^{1-3}$ About half of survivors of pneumococcal meningitis have neurologic sequelae, including hearing loss, focal cerebral deficits, and cognitive impairment. ${ }^{4-7} \mathrm{Un}$ favorable outcome after meningitis is mainly caused by an excessive inflammation reaction of the host's immune system in reaction to the bacterial infection, leading to injury to the CNS. ${ }^{8,9}$ Brain autopsy of pneumococcal meningitis cases has shown that vascular damage is key in the process of cortical necrosis and brain damage. ${ }^{10}$ The use of an objective and dynamic fluid biomarker for neuronal damage might provide clinicians with an additional tool for prognostic assessment.

Neurofilaments are cylindrical proteins that are exclusively located in the neuronal cytoplasm and form an integral component of the axonal cytoskeleton. ${ }^{11}$ Neurofilaments consist of 3 subunits: neurofilament light chain (NfL), heavy chain, and medium chain. As NfL is the backbone of neurofilaments, it can be robustly measured in body fluids. Although low concentrations of $\mathrm{NfL}$ are continuously being released in an age-dependent manner from axons, a wide variety of CNS diseases that cause axonal damage result in elevated NfL concentrations proportionally to the degree of axonal damage. ${ }^{12}$ This includes multiple sclerosis (MS), frontotemporal dementia (FTD), and amyotrophic lateral sclerosis (ALS), in which NfL has been suggested to be valuable not only in diagnosis (ALS) but also as a serum marker of disease progression (FTD and ALS) and treatment response (MS). ${ }^{11-14}$ Few studies have described neurofilaments in CNS infections, ${ }^{15,16}$ with a study in children with bacterial meningitis showing that peak concentrations of neurofilament heavy chain in CSF were higher in patients with neurologic sequelae than in those without. ${ }^{17}$ In an experimental pneumococcal rat model, CSF NfL concentrations were increased after injection with experimental $S$. pneumoniae compared with mock-infected rats. ${ }^{18}$

Our objective was to determine the prognostic accuracy of NfL in bacterial meningitis in adults. We hypothesized that $\mathrm{NfL}$ in CSF might be increased in patients with bacterial meningitis and that the quantification of neuronal damage could allow for prognostic assessment. In this prospective nationwide cohort study, we evaluated the prognostic value of concentrations of NfL in CSF in adults with communityacquired bacterial meningitis.

\section{Methods}

\section{Patients}

The MeninGene study is an ongoing nationwide cohort study in The Netherlands that started in 2006 to identify host and pathogen factors influencing the risk and outcome of bacterial meningitis. ${ }^{2,19,20}$ Detailed methods of the cohort have been described previously. ${ }^{2}$ In summary, patients aged 16 years or older with community-acquired bacterial meningitis were prospectively included following a report from the Netherlands Reference Laboratory for Bacterial Meningitis. This laboratory receives bacterial strains from over $85 \%$ of all patients with bacterial meningitis in the Netherlands and notifies the investigators with the name of the treating physicians, who are then contacted to include the patient in the study. Written informed consent was obtained from participating patients or their legal representatives.

\section{Inclusion and Exclusion Criteria}

Patients were included in the MeninGene study if they had a positive CSF culture or if the CSF showed at least 1 individual finding predictive of bacterial meningitis according to the Spanos criteria (glucose $<1.9 \mathrm{mmol} / \mathrm{L}$, CSF serum glucose ratio $<0.23$, protein concentration $>2.20 \mathrm{~g} / \mathrm{L}$, white cell count $>2,000$ cells $/ \mathrm{mm}^{3}$, or CSF neutrophil count $>1,180$ cells $\left./ \mathrm{mm}^{3}\right)^{21}$ in combination with a positive CSF PCR, CSF antigen, or blood culture. Patients who developed meningitis while in hospital or within 1 week after discharge, following head trauma or neurosurgery in the previous month, or with a neurosurgical device in situ were excluded. ${ }^{22}$

\section{Neurofilament Light Chain (NfL) Measurement in CSF}

CSF from the diagnostic lumbar puncture (at presentation or on admission) was collected in a central biobank in Amsterdam UMC and was available for $\pm 60 \%$ of included episodes. After withdrawal, the samples were centrifuged, frozen, and stored in 96-well plates at $-80^{\circ} \mathrm{C}$ until further analysis. For the current measurements, $6 \mathrm{CSF}$ plates were randomly selected. NfL in CSF $(5 \mu \mathrm{L})$ was measured using the Simoa NF-light Advantage Kit (ref. 103186) on an HD-X instrument (Quanterix, Billerica, MA) at the Neurochemistry Laboratory at Amsterdam UMC, location VUmc, according to the manufacturer's instructions.

Quality of the assay is monitored using 3 serum pools from patients, having different NfL levels spanning the measurement range. The interassay coefficient of variability over 146 runs was $7.7 \%$. The intra-assay variation of the assays has been extensively tested, being consistently $<3 \%$.

\section{Clinical Data Collection and Definitions}

Data on patients' baseline characteristics, symptoms on admission, clinical course, treatment, and (neurologic) outcome were prospectively collected with a secured online case record form. Immunocompromised state was defined as having active cancer, a splenectomy, diabetes mellitus, HIV, alcoholism, or the use of immunosuppressive drugs. At discharge, neurologic 
Table 1 Baseline and Clinical Characteristics of the Neurofilament Light Chain (NfL) Cohort (Total, N = 429)

\begin{tabular}{|c|c|c|c|}
\hline Characteristic & Data & Characteristic & Data \\
\hline Age, $y^{a}$ & $62(50-69)$ & Blood and CSF culture & \\
\hline Female sex & $210 / 429(49 \%)$ & Positive blood culture & $288 / 376(77 \%)$ \\
\hline Symptoms $<24 \mathrm{~h}$ & 196/403 (49\%) & Positive CSF culture & $400 / 429(93 \%)$ \\
\hline Recurrent meningitis & $28 / 428(7 \%)$ & Causative pathogen & \\
\hline Previously diagnosed infection & $192 / 422(46 \%)$ & S. pneumoniae & $314 / 429(73 \%)$ \\
\hline Otitis or sinusitis & $163 / 405(40 \%)$ & N. meningitidis & $32 / 429(7 \%)$ \\
\hline Pneumonia & $27 / 406(7 \%)$ & L. monocytogenes & $21 / 429(5 \%)$ \\
\hline Endocarditis & $6 / 399(2 \%)$ & Other & $62 / 429(14 \%)$ \\
\hline Immunocompromised state & $111 / 427(26 \%)$ & Indices of CSF inflammation & \\
\hline Cancer & $59 / 427(14 \%)$ & Opening pressure (cm water) $)^{j}$ & $36(23-43)$ \\
\hline Diabetes & $43 / 421(10 \%)$ & Protein $(\mathrm{g} / \mathrm{L})^{\mathrm{k}}$ & $4(2.2-6.3)$ \\
\hline Alcoholism & $21 / 424(5 \%)$ & CSF/serum glucose ratio' & $0.07(0.01-0.26)$ \\
\hline Immunosuppressive treatment & $41 / 421(10 \%)$ & White cell count per $\mathrm{mm}^{\mathrm{m}}$ & $2,233(577-5,697)$ \\
\hline Splenectomy & $12 / 426(3 \%)$ & $<100 / \mathrm{mm}^{3}$ & $50 / 412(12 \%)$ \\
\hline Other predisposing factors & & $100-999 / \mathrm{mm}^{3}$ & $90 / 412(22 \%)$ \\
\hline CSF leak & $15 / 418(4 \%)$ & $>999 / \mathrm{mm}^{3}$ & $272 / 412(66 \%)$ \\
\hline Remote head trauma & $14 / 402(4 \%)$ & Radiologic examination & \\
\hline Clinical signs and symptoms & & Abnormal brain $\mathrm{CT}$ or MRI & $166 / 374(44 \%)$ \\
\hline Median temperature $^{\mathrm{b}}$ & $38.8(37.9-39.7)$ & Adjunctive dexamethasone therapy & $364 / 414(88 \%)$ \\
\hline Classic triad & 152/399 (38\%) & Clinical course & \\
\hline Fever $\left(>38^{\circ} \mathrm{C}\right)$ & $291 / 366(80 \%)$ & Cardiorespiratory failure & $108 / 406(27 \%)$ \\
\hline Headache & $296 / 362(82 \%)$ & Seizures & $63 / 403(16 \%)$ \\
\hline Neck stiffness & 283/392 (72\%) & Pneumonia & $54 / 400(14 \%)$ \\
\hline Nausea & $200 / 329(61 \%)$ & Cerebrovascular accident & $51 / 395(13 \%)$ \\
\hline Glasgow Coma Scale score ${ }^{c}$ & $11(9-14)$ & Glasgow Outcome Score & \\
\hline Altered mental status (GCS score <14) & $290 / 422(68 \%)$ & 1 (death) & $62 / 429(15 \%)$ \\
\hline Coma (GCS score $\leq 8$ ) & $75 / 422(18 \%)$ & 2 (vegetative state) & $2 / 429(1 \%)$ \\
\hline Aphasia, monoparesis, or hemiparesis & $76 / 348(22 \%)$ & 3 (severe disability) & $21 / 429(5 \%)$ \\
\hline Seizures & $33 / 402(8 \%)$ & 4 (moderate disability) & $72 / 429(17 \%)$ \\
\hline Babinski reflex & $55 / 357(15 \%)$ & 5 (mild or no disability) & $272 / 429(63 \%)$ \\
\hline Cranial nerve palsies & $27 / 365(7 \%)$ & Neurologic sequelae at discharge & \\
\hline Heart rate (beats $/ \mathrm{min})^{d}$ & $99(84-114)$ & Hearing impairment & $101 / 343(29 \%)$ \\
\hline Systolic blood pressure $(\mathrm{mm} \mathrm{Hg})^{e}$ & $145(128-163)$ & Cognitive impairment & $65 / 284(23 \%)$ \\
\hline Diastolic blood pressure $(\mathrm{mm} \mathrm{Hg})^{f}$ & $80(70-90)$ & Cranial nerve palsy & $43 / 287(15 \%)$ \\
\hline Blood chemical tests & & Focal cerebral deficits & $38 / 269$ (14\%) \\
\hline
\end{tabular}


Table 1 Baseline and Clinical Characteristics of the Neurofilament Light Chain (NfL) Cohort (Total, N = 429) (continued)

\begin{tabular}{llll}
\hline Characteristic & Data & Characteristic & Data \\
\hline C-reactive protein $(\mathrm{mg} / \mathrm{L})^{\mathrm{g}}$ & $167(76-288)$ & Mono- or hemiparesis & 26/284 (9\%) \\
\hline Thrombocyte count $(\mathrm{per} \mu \mathrm{L})^{\mathrm{h}}$ & $195(153-251)$ & Aphasia & $15 / 289(5 \%)$ \\
\hline${\text { Leukocyte count }(\text { per } \mu \mathrm{L})^{\mathrm{i}}}$ & $16(13-22)$ & Days to discharge $^{\mathrm{n}}$ & $12(11-14)$ \\
\hline
\end{tabular}

Abbreviations: ICU = intensive care unit; $\mathrm{LP}=$ lumbar puncture.

Data are median (IQR) or $\mathrm{n} / \mathrm{N}(\%)$

a Age known in all episodes.

b Temperature known for 395 episodes.

' Glasgow Coma Scale score known for 422 episodes.

d Heart rate is known for 395 episodes.

e Systolic blood pressure known for 395 episodes.

${ }^{\mathrm{f}}$ Diastolic blood pressure known for 395 episodes.

${ }^{\mathrm{g}}$ C-reactive protein known for 415 episodes.

${ }^{\text {h }}$ Thrombocyte count known for 401 episodes.

' Leukocyte count know for 421 episodes.

j Opening pressure known for 118 episodes.

k Protein known for 406 episodes.

' CSF/serum glucose ratio known for 379 episodes.

$m$ White cell count in CSF known for 412 episodes.

${ }^{n}$ Days to discharge known for 354 episodes.

examination was assessed using the Glasgow Outcome Scale (GOS) score, ranging from a score of $1=$ death to a score of $5=$ mild or no disability (able to return to work or school). An unfavorable outcome was defined as a GOS score of $1-4$, and a favorable outcome was defined as a score of 5 .

\section{Statistical Analysis}

Categorical variables are expressed as counts and proportions, and continuous variables are expressed as median with interquartile range (IQR). CSF NfL concentrations between groups were compared using the Mann-Whitney $U$ test or the KruskalWallis test. Logistic regression was used to analyze the association between CSF NfL level with unfavorable outcome, providing ORs and 95\% CIs. We chose possible confounding variables for $\mathrm{NfL}$ and predictors of an unfavorable outcome on the basis of previous research ${ }^{2}$ and pathophysiologic interest. Linearity of the association between continuous predictors and outcome was assessed with the Hosmer-Lemeshow goodness of fit test and by visual inspection. If there was no linear relationship, the continuous predictor was either transformed or categorized for further analysis. We estimated both univariable and multivariable ORs corrected for all other variables in the model. We used multiple imputation for missing data in the multivariable analysis and used all predictors together to impute missing values. For the multivariable model, missing values in the selected prognostic factors (median 4.9\% per prognostic factor [IQR 3.9-6.6]) were imputed, subsequently combining the coefficients of each data set $(\mathrm{N}=5)$ according to Rubin rule. ${ }^{23}$ All tests were 2 tailed, and a $p$ value $<0.05$ was considered significant. Statistical analysis was conducted using IBM SPSS Statistics data Editor (v.26).

\section{Standard Protocol Approvals, Registrations, and Patient Consents}

This study was approved by the Medical Ethical Review Committee of the Amsterdam UMC (number METC 2013_043). Written informed consent was obtained from all participants or their representatives.

\section{Data Availability}

Anonymized data not published within the article will be shared on the request from any qualified investigator.

\section{Results}

Between 2006 and July 2018, a total of 2,116 episodes of bacterial meningitis were included in our cohort study. For the current analyses, we used 429 episodes with an available CSF sample from the diagnostic lumbar puncture (eFigure 1, links.lww.com/NXI/A673). Characteristics between selected and nonselected patients for this analysis were similar (eTable 1, links.lww.com/NXI/A673). The 429 episodes occurred in 425 patients; 4 patients had recurrent meningitis within the cohort study period.

The median patient age in the 429 episodes was 62 years (IQR 50-69 years), and 210 of 429 episodes occurred in females (49\%; Table 1). Immunocompromising conditions were present in 111 of $427(26 \%)$ of episodes, predisposing infection foci in 192 of 422 (46\%) episodes, and 15 of 418 (4\%) of episodes had a CSF leak. An altered mental status (defined as Glasgow Coma Scale [GCS] score <14) was present on admission in 290 of 422 (68\%) episodes, of whom 75 episodes presented with coma (GCS score $<8)$. The classical triad consisting of fever, altered mental status, and neck stiffness was present in 152 of 399 episodes (38\%). Streptococcus pneumoniae and Neisseria meningitidis were the most common causative pathogens causing 314 of 429 (73\%) and 32 of $429(7 \%)$ of the cases. An unfavorable outcome occurred in 157 of 429 (37\%) of episodes, and 62 of 429 $(15 \%)$ patients died. Most common neurologic sequelae at discharge were hearing impairment (101 of 343 episodes, $29 \%$ ), cognitive impairment (65 of 284 episodes, $23 \%$ ), cranial nerve palsies ( 43 of 287 episodes, $15 \%$ ), and focal cerebral deficits (38 of 269 episodes, 14\%). 
Figure 1 Comparison of NfL Level (Median) in CSF Between Different Causative Pathogens

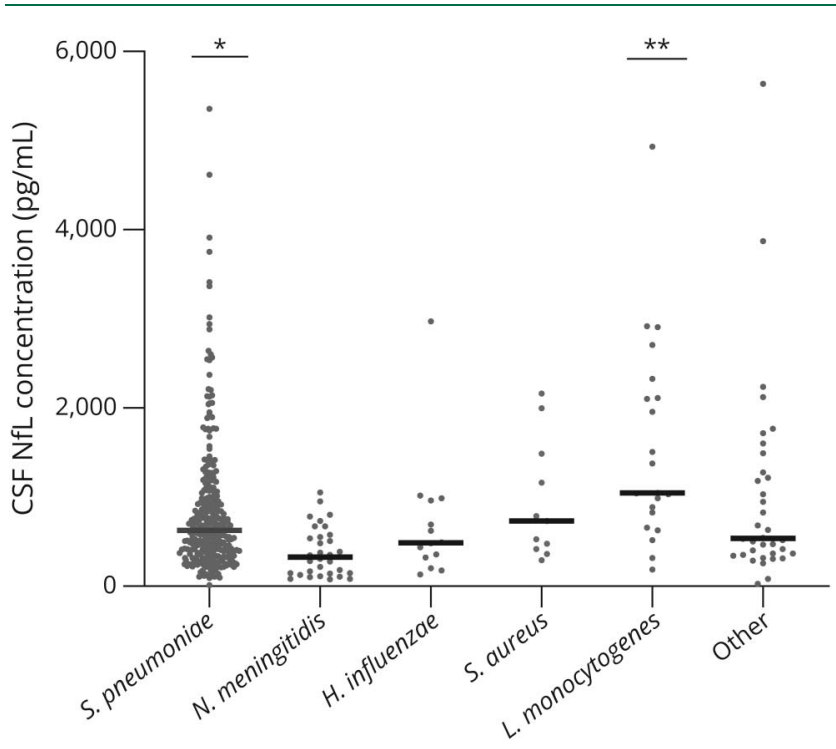

*Significant difference in NfL level between pneumococcal ( $N=314$ ) vs nonpneumococcal $(\mathrm{N}=115)$ cases, after correction for age (respectively, 616 $\mathrm{pg} / \mathrm{mL}$ [IQR 361-1,043 pg/mL] and $541 \mathrm{pg} / \mathrm{mL}$ [IQR 319-1,054 pg/mL], $F[1,426]=3.93, p=0.048)$ **Significant difference in NfL level between Listeria monocytogenes ( $\mathrm{N}=21)$ vs non-Listeria $(\mathrm{N}=408)$ cases, after correction for age (respectively, 1,049 pg/mL [IQR 741-2,219 pg/mL] and $572 \mathrm{pg} / \mathrm{mL}$ [IQR $342-1,007 \mathrm{pg} / \mathrm{mL}], F[1,426]=6.29, p=0.013)$. Haemophilus influenzae $(\mathrm{N}=13)$ and Staphylococcus aureus $(\mathrm{N}=11)$. Other pathogens: Streptococcus agalactiae $(\mathrm{N}=7)$, Streptococcus pyogenes $(\mathrm{N}=11)$, Streptococcus suis $(\mathrm{N}=3)$, Streptococcus salivarius $(\mathrm{N}=2)$, Streptococcus anginosus $(\mathrm{N}=3)$, Streptococcus dysgalactiae $(\mathrm{N}=1)$, Streptococcus intermedius $(\mathrm{N}=2)$, Streptococcus oralis $(\mathrm{N}=1)$, Escherichia coli $(\mathrm{N}=2)$, Klebsiella pneumoniae $(\mathrm{N}=1)$, Campylobacter fetus $(\mathrm{N}=1)$, Nocardia farcinica $(\mathrm{N}=1)$, Group $\mathrm{C}$ streptococcus not other specified $(\mathrm{N}=1)$, viridans group streptococci not other specified $(\mathrm{N}=1)$, and Fusobacterium necrophorum $(N=1) . I Q R=$ interquartile range; $N f L=$ neurofilament light chain

The median CSF NfL concentration was $600 \mathrm{pg} / \mathrm{mL}$ (IQR 348-1,047 pg/mL). A moderate correlation was found between CSF NfL concentrations and age $(\mathrm{r}=0.6, p<0.001)$, and a weak correlation between CSF NfL and CSF protein concentrations $(r=0.14, p=0.009)$ and CSF NfL and CSF leukocyte counts $(\mathrm{r}=-0.2, p<0.001)$. NfL concentrations were higher in patients presenting with focal cerebral deficits (717 $\mathrm{pg} / \mathrm{mL}[416-1,401]$ vs $412 \mathrm{pg} / \mathrm{mL}$ [278-731] without focal cerebral deficits; $p<0.001)$ and those presenting with a GCS score $<14$ (NfL $654 \mathrm{pg} / \mathrm{mL}$ [IQR 397-1,083 pg/mL] vs 513 $\mathrm{pg} / \mathrm{mL}$ [IQR $271-873 \mathrm{pg} / \mathrm{mL}]$ in those presenting with a GCS score of 14 and 15; $p=0.002$ ). CSF NfL concentrations differed between causative pathogens (Figure 1). CSF NfL concentrations were higher in patients with pneumococcal meningitis compared with nonpneumococcal meningitis (median NfL 616 pg/mL [IQR 361-1,043 pg/mL] vs $541 \mathrm{pg} / \mathrm{mL}$ [IQR 319-1,054 pg/mL], after correcting for age $p=0.048)$.

CSF NfL concentrations in patients who died were more than 2-fold higher than in surviving patients $(1,152 \mathrm{pg} / \mathrm{mL}$ [IQR 594-2043 pg/mL] vs $541 \mathrm{pg} / \mathrm{mL}$ [IQR 335-924 pg/mL], $p<$ 0.001; Figure 2). CSF NfL concentrations were higher in patients with an unfavorable outcome (928 pg/mL [IQR 494-1765 $\mathrm{pg} / \mathrm{mL}$ ] vs $506 \mathrm{pg} / \mathrm{mL}$ [IQR $314-809 \mathrm{pg} / \mathrm{mL}$ ], $p<0.001)$. In a multivariable analysis, older age, cranial nerve palsy, high serum C-reactive protein concentration, and high CSF NfL concentration were associated with an unfavorable outcome in bacterial meningitis due to any pathogen (Table 2). The association between CSF NfL concentration and outcome remained robust when including the causative pathogen (eTable 2, links.lww.com/ NXI/A673). The area under the curve (AUC) for predicting unfavorable outcome in bacterial meningitis was 0.69 (95\% CI 0.64-0.74). The optimal cutoff point in CSF NfL concentration according to the Youden index was $681 \mathrm{pg} / \mathrm{mL}$ (sensitivity $63 \%$ and specificity 67\%). The AUC for predicting mortality in bacterial meningitis was 0.72 (95\% CI $0.65-0.79)$, with an optimal cutoff point of $926 \mathrm{pg} / \mathrm{mL}$ (sensitivity $67 \%$ and specificity $75 \%$ ).

\section{Discussion}

Our study shows that CSF NfL concentration independently predicts unfavorable outcome in adults with community-

Figure 2 Comparison of NfL Level Between Total Cohort ( $N=429$ ) and Different Outcome Groups (Median, Interquartile Range)

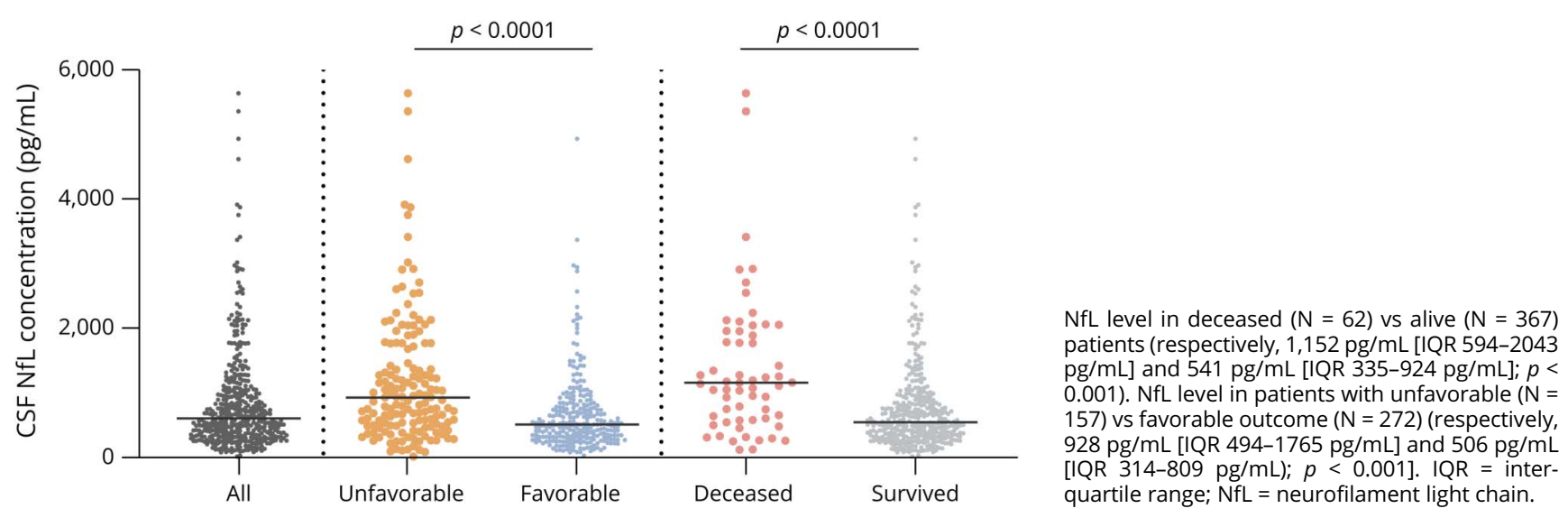


Table 2 Factors Associated With an Unfavorable Outcome

\begin{tabular}{|c|c|c|c|c|c|}
\hline & $\begin{array}{l}\text { Favorable } \\
\text { outcome } \\
(\mathrm{N}=\mathbf{2 7 2})\end{array}$ & $\begin{array}{l}\text { Unfavorable } \\
\text { outcome } \\
\text { ( } N=157)\end{array}$ & $\begin{array}{l}\text { Univariable OR } \\
\text { unfavorable } \\
\text { outcome }(95 \% \mathrm{Cl})\end{array}$ & $\begin{array}{l}\text { Multivariable OR } \\
\text { unfavorable } \\
\text { outcome }(95 \% \mathrm{Cl})\end{array}$ & $\begin{array}{l}p \text { Value } \\
\text { multivariable } \\
\text { analysis }\end{array}$ \\
\hline $\mathrm{NfL}$ in CSF (pg/mL) & $506(314-809)$ & $928(494-1765)$ & $2.1(1.6-2.7)$ & $1.6(1.2-2.2)$ & 0.004 \\
\hline Age $(y)^{b}$ & $59(46-66)$ & $66(57-74)$ & $1.04(1.03-1.06)$ & $1.03(1.01-1.05)$ & 0.007 \\
\hline Otitis or sinusitis & $111 / 261(43 \%)$ & $52 / 144(36 \%)$ & $0.84(0.53-1.3)$ & $0.96(0.6-1.6)$ & 0.89 \\
\hline Pneumonia & $14 / 263(5 \%)$ & $13 / 143(9 \%)$ & $2.1(1-4.4)$ & $1(0.4-2.5)$ & 1 \\
\hline Immunocompromised state & $62 / 271(23 \%)$ & 49/156 (31\%) & $1.5(1-2.2)$ & $1.3(0.8-2.2)$ & 0.24 \\
\hline Rash & $17 / 250(6.8 \%)$ & $9 / 129(7 \%)$ & $1.1(0.5-2.6)$ & $1.9(0.6-6)$ & 0.25 \\
\hline Cranial nerve palsy & 9/244 (4\%) & 18/121 (15\%) & $4.6(2.0-10.5)$ & $4(1.6-10.3)$ & 0.004 \\
\hline Mono-, hemiparesis, or aphasia & 44/227 (19\%) & $32 / 121(26 \%)$ & $2.5(1.4-4.3)$ & $1.7(0.9-3.2)$ & 0.14 \\
\hline Heart rate $(\text { per } 10 \mathrm{bpm})^{c}$ & $97(82-109)$ & $104(84-120)$ & $1.2(1.07-1.3)$ & $1.1(1.0-1.2)$ & 0.10 \\
\hline Glasgow Coma Scale score ${ }^{d}$ & $13(10-14)$ & $10(9-13)$ & $0.84(0.8-0.9)$ & $0.9(0.8-1.03)$ & 0.16 \\
\hline C-reactive protein $(\mathrm{mg} / \mathrm{L})^{\mathrm{e}}$ & $140(62-250)$ & $212(117-337)$ & $1.04(1.03-1.05)$ & $1.03(1.01-1.05)$ & 0.001 \\
\hline Thrombocyte count (*109/L) & $198(160-251)$ & $183(143-252)$ & - & - & - \\
\hline$<150$ & $53 / 261(20 \%)$ & $41 / 140(29 \%)$ & $1.7(1.07-2.7)$ & $1.4(0.8-2.5)$ & 0.24 \\
\hline $150-450$ & $204 / 261(78 \%)$ & $98 / 140(70 \%)$ & Reference & Reference & - \\
\hline$>450$ & $4 / 261(2 \%)$ & $1 / 140(1 \%)$ & $0.6(0.07-5.8)$ & $0.6(0.03-9.5)$ & 0.71 \\
\hline White cell count in CSF (per $\mu \mathrm{L}$ ) & $2,448(815-6,380)$ & $1,667(280-5,072)$ & - & - & - \\
\hline$<100$ & $22 / 259(8 \%)$ & 25/153 (16\%) & $2.3(1.2-4.4)$ & $0.9(0.4-2.2)$ & 0.89 \\
\hline 100-999 & $53 / 259(20 \%)$ & $37 / 153(24 \%)$ & $1.4(0.9-2.4)$ & $0.97(0.5-1.7)$ & 0.92 \\
\hline $1,000-10,000$ & $149 / 259(55 \%)$ & $74 / 153(48 \%)$ & Reference & Reference & - \\
\hline$>10,000$ & $35 / 259(13 \%)$ & 17/153 (11\%) & $1(0.5-2)$ & $0.7(0.3-1.6)$ & 0.45 \\
\hline CSF:blood glucose ratio ${ }^{f}$ & $0.1(0.01-0.3)$ & $0.02(0.01-0.2)$ & $0.2(0.02-1.2)$ & $0.5(0.08-3.6)$ & 0.51 \\
\hline Positive blood culture & $174 / 235(74 \%)$ & $114 / 141(81 \%)$ & $1.5(0.9-2.5)$ & $1(0.6-1.8)$ & 0.97 \\
\hline
\end{tabular}

Data are median (interquartile range) or $\mathrm{n} / \mathrm{N}(\%)$. The multivariable analysis used an imputed data set with 5 imputation rounds; all variables in the table were entered in the multivariable logistic regression model simultaneously.

${ }^{a} \mathrm{OR}$ is for each increase in the natural logarithm in $\mathrm{NfL}(\mathrm{pg} / \mathrm{mL})$.

${ }^{\mathrm{b}}$ Age is known for all episodes.

c Heart rate is known for 403 episodes.

d Glasgow Coma Scale score known for 422 episodes.

e C-reactive protein is known for 415 episodes; OR is for a $10 \mathrm{mg} / \mathrm{L}$ increase.

$\mathrm{f}$ CSF:blood glucose ratio is known for 379 episodes.

acquired bacterial meningitis. Previous studies have identified several predictors for unfavorable outcome in bacterial meningitis ${ }^{2,3,24,25}$ : a low level of consciousness on admission, cranial nerve palsy, a low CSF white cell count, factors predictive of pneumococcal infection (advanced age; presence of otitis or sinusitis, pneumonia, or immunocompromised status; and absence of rash) or systemic compromise (high heart rate and high serum C-reactive protein concentration), and infection by a penicillin-resistant $S$. pneumoniae. ${ }^{26}$ As neuronal damage plays a central role in the pathophysiology of bacterial meningitis, ${ }^{9}$ the use of a body fluid biomarker for neuronal damage such as NfL might provide clinicians with an additional tool for better prognostic assessment and could aid to identify those patients at risk for an unfavorable outcome.
In bacterial meningitis, outcome is in part determined by an excessive inflammation reaction of the host's immune system in reaction to the bacterial infection, ${ }^{8,9}$ causing vascular and neuronal damage. ${ }^{10}$ In previous studies, NfL was shown to predict outcome and disease progression in a wide variety of neurologic disorders such as Guillain-Barre syndrome, ${ }^{27}$ amyotrophic lateral sclerosis, ${ }^{28,29}$ critical illness neuropathy in intensive care patients, ${ }^{30}$ Alzheimer disease, ${ }^{31}$ FTD,${ }^{32}$ chronic inflammatory demyelinating polyneuropathy, ${ }^{33}$ and MS. ${ }^{34,35}$ Furthermore, plasma NfL concentrations demonstrated excellent prognostic accuracy in comatose patients after outof-hospital cardiac arrest. ${ }^{36,37}$ The prognostic value of neurofilaments in CNS infections has been studied previously. Two studies showed higher serum and CSF NfL levels in 
patients with varicella zoster virus encephalitis compared with varicella zoster virus meningitis. ${ }^{15,16}$ One study showed higher CSF concentrations of neurofilament heavy chain in 26 children with bacterial meningitis compared with controls. ${ }^{17}$

Results of this study show that the diagnostic accuracy of CSF NfL concentrations for predicting death or unfavorable outcome on an individual patient level is limited. Although NfL levels are higher in patients with an unfavorable outcome, the ranges overlap to an extent that makes it difficult to define a pathologic cutoff at the individual patient level, which is also reflected by the moderate AUC. Nevertheless, NfL in CSF might be a potential useful variable in a prediction model for unfavorable outcome in bacterial meningitis. Several previous studies have researched such prediction models and prognostics factors in bacterial meningitis. ${ }^{38,39}$ Improving the stratification of patients with bacterial meningitis at presentation with respect to the risk for unfavorable outcome remains an important tool for physicians to predict clinical deterioration, but can also be a valuable tool for targeting intervention strategies, e.g., as stratification marker or outcome measure. The use of a marker for neuroaxonal damage such as $\mathrm{NfL}$ might be specifically interesting, as unfavorable outcome in bacterial meningitis is mainly caused by intracranial complications, and thus, the marker likely reflects downstream biological effects. $^{1,4,9}$ Future studies should therefore consider to evaluate the added value of NfL in predictor models for bacterial meningitis.

Our study has limitations. First, NfL was not measured in all patients included in the MeninGene cohort, but only in a limited number of samples. CSF samples from the diagnostic lumbar puncture are stored in about $60 \%$ of patients included in the cohort. However, baseline characteristics between episodes selected and not selected for the study were similar, indicating that the influence of selection bias on our results is limited. Second, NfL concentrations were measured in the CSF of the diagnostic lumbar puncture only. For better prognostic assessment, measuring several time points, for example, in plasma, might provide additional information on disease progression, as has been shown in some previous studies. ${ }^{29,31,34,40}$ For several neurodegenerative diseases, a strong correlation between CSF and plasma NfL has been demonstrated. ${ }^{14,35}$ Also, in an experimental pneumococcal meningitis model, CSF and plasma NfL showed strong correlation. ${ }^{18}$ Future studies should therefore evaluate the prognostic value of serial plasma NfL measurement in bacterial meningitis. ${ }^{17,18}$ Third, the exact time to clinical presentation from symptom onset in our cohort is not known, which would possibly be of interest as the level of NfL might differ over time.

In conclusion, CSF NfL concentrations are independently associated with unfavorable outcome in adults with communityacquired bacterial meningitis. Future studies should evaluate the added value of NfL in prediction models for bacterial meningitis.

\section{Study Funding}

This work was supported by the Netherlands Organization for Health Research and Development (ZonMw; NWO-Vidi Grant [917.17.308] to M.C.B; NWO-Vici-Grant [grant number 918.19.627 to D. B.]); the Academic Medical Center (AMC Fellowship to D. B); and the European Research Council (ERC Consolidator grant to M.C.B., ERC Starting grant to D. B). The Netherlands Reference Laboratory for Bacterial Meningitis is supported by the National Institute of Public Health and the Environmental Protection, Bilthoven.

\section{Disclosure}

None. Go to Neurology.org/NN for full disclosures.

\section{Publication History}

Received by Neurology: Neuroimmunology \& Neuroinflammation September 3, 2021. Accepted in final form November 1, 2021.

\begin{tabular}{|c|c|c|}
\hline Name & Location & Contribution \\
\hline $\begin{array}{l}\text { Nora } \\
\text { Chekrouni, } \\
\text { MD }\end{array}$ & $\begin{array}{l}\text { Amsterdam UMC, University of } \\
\text { Amsterdam, Department of } \\
\text { Neurology, Amsterdam } \\
\text { Neuroscience, Meibergdreef, } \\
\text { Amsterdam, The Netherlands }\end{array}$ & $\begin{array}{l}\text { Drafting/revision of the } \\
\text { manuscript for content, } \\
\text { including medical writing } \\
\text { for content; major role in } \\
\text { the acquisition of data; } \\
\text { study concept or design; } \\
\text { and analysis or } \\
\text { interpretation of data }\end{array}$ \\
\hline
\end{tabular}

Thijs M. van Amsterdam UMC, University of Drafting/revision of the Soest, MD Amsterdam, Department of manuscript for content, Neurology, Amsterdam including medical writing Neuroscience, Meibergdreef, for content; major role in Amsterdam, The Netherlands the acquisition of data; and analysis or interpretation of data

Matthijs C. Amsterdam UMC, University of Drafting/revision of the Brouwer, Amsterdam, Department of manuscript for content, MD-PhD Neurology, Amsterdam including medical writing Neuroscience, Meibergdreef, for content; major role in Amsterdam, The Netherlands the acquisition of data; study concept or design; and analysis or interpretation of data

\begin{tabular}{lll}
\hline Eline A.J. & Amsterdam UMC, Vrije & $\begin{array}{l}\text { Study concept or design } \\
\text { Willemse, }\end{array}$ \\
USc & Amiversiteit Amsterdam, & $\begin{array}{l}\text { and analysis or } \\
\text { interpretation of data }\end{array}$ \\
& Neurochemistry Laboratory, & \\
& Department of Clinical & \\
& Chemistry, De Boelelaan 1117, \\
& Amsterdam, The Netherlands
\end{tabular}

Charlotte E. Amsterdam UMC, Vrije

Teunissen, Universiteit Amsterdam,

PhD Amsterdam Neuroscience, Neurochemistry Laboratory, Department of Clinical

Drafting/revision of the manuscript for content, including medical writing for content; study concept or design; and analysis or Chemistry, De Boelelaan 1117, interpretation of data Amsterdam, The Netherlands

Diederik van Amsterdam UMC, University of Drafting/revision of the de Beek, Amsterdam, Department of manuscript for content, MD-PhD Neurology, Amsterdam including medical writing Neuroscience, Meibergdreef, for content; major role in Amsterdam, The Netherlands the acquisition of data; study concept or design; and analysis or interpretation of data 


\section{References}

1. van de Beek D, Brouwer M, Hasbun R, Koedel U, Whitney CG, Wijdicks E. Community-acquired bacterial meningitis. Nat Rev Dis Primers. 2016;2:16074

2. Bijlsma MW, Brouwer MC, Kasanmoentalib ES, et al. Community-acquired bacterial meningitis in adults in The Netherlands, 2006-14: a prospective cohort study. Lancet Infect Dis. 2016;16(3):339-347.

3. van de Beek D, de Gans J, Spanjaard L, Weisfelt M, Reitsma JB, Vermeulen M. Clinical features and prognostic factors in adults with bacterial meningitis. N Engl J Med. 2004; 351(18):1849-1859.

4. Lucas MJ, Brouwer MC, van de Beek D. Neurological sequelae of bacterial meningitis. J Infect. 2016;73(1):18-27.

5. Hoogman M, van de Beek D, Weisfelt M, de Gans J, Schmand B. Cognitive outcome in adults after bacterial meningitis. J Neurol Neurosurg Psychiatry. 2007;78(10): 1092-1096.

6. van de Beek D, de Gans J, Tunkel AR, Wijdicks EFM. Community-acquired bacterial meningitis in adults. New Engl J Med. 2006;354(1):44-53.

7. Kloek AT, Brouwer MC, Schmand B, Tanck MWT, van de Beek D. Long-term neurologic and cognitive outcome and quality of life in adults after pneumococcal meningitis. Clin Microbiol Infect. 2020;26(10):1361-1367.

8. Koelman DLH, Brouwer MC, van de Beek D. Targeting the complement system in bacterial meningitis. Brain. 2019;142(11):3325-3337.

9. Mook-Kanamori BB, Geldhoff M, van der Poll T, van de Beek D. Pathogenesis and pathophysiology of pneumococcal meningitis. Clin Microbiol Rev. 2011;24(3): 557-591.

10. Engelen-Lee JY, Brouwer MC, Aronica E, van de Beek D. Pneumococcal meningitis: clinical-pathological correlations (MeninGene-Path). Acta Neuropathol Commun. 2016;4:26.

11. Gaetani L, Blennow K, Calabresi P, Di Filippo M, Parnetti L, Zetterberg H. Neurofilament light chain as a biomarker in neurological disorders. J Neurol Neurosurg Psychiatry. 2019;90(8):870-881

12. Bridel C, van Wieringen WN, Zetterberg H, et al. Diagnostic value of cerebrospinal fluid neurofilament light protein in neurology: a systematic review and meta-analysis. JAMA Neurol. 2019;76(9):1035-1048.

13. Disanto G, Barro C, Benkert P, et al. Serum Neurofilament light: a biomarker of neuronal damage in multiple sclerosis. Ann Neurol. 2017;81(6):857-870.

14. Khalil M, Teunissen CE, Otto M, et al. Neurofilaments as biomarkers in neurological disorders. Nat Rev Neurol. 2018;14(10):577-589.

15. Grahn A, Hagberg L, Nilsson S, Blennow K, Zetterberg H, Studahl M. Cerebrospinal fluid biomarkers in patients with varicella-zoster virus CNS infections. J Neurol. 2013; 260(7):1813-1821.

16. Tyrberg T, Nilsson S, Blennow K, Zetterberg H, Grahn A. Serum and cerebrospinal fluid neurofilament light chain in patients with central nervous system infections caused by varicella-zoster virus. J Neurovirol. 2020;26(5):719-726.

17. Matsushige T, Ichiyama T, Kajimoto M, Okuda M, Fukunaga S, Furukawa S. Serial cerebrospinal fluid neurofilament concentrations in bacterial meningitis. J Neurol Sci. 2009;280(1-2):59-61.

18. Le ND, Muri L, Grandgirard D, Kuhle J, Leppert D, Leib SL. Evaluation of neurofilament light chain in the cerebrospinal fluid and blood as a biomarker for neuronal damage in experimental pneumococcal meningitis. J Neuroinflammation. 2020;17(1): 293.

19. Koopmans MM, Bijlsma MW, Brouwer MC, van de Beek D, van der Ende A. Listeria monocytogenes meningitis in The Netherlands, 1985-2014: a nationwide surveillance study. J Infect. 2017;75(1):12-19.
20. Brouwer MC, Heckenberg SG, de Gans J, Spanjaard L, Reitsma JB, van de Beek D. Nationwide implementation of adjunctive dexamethasone therapy for pneumococcal meningitis. Neurology. 2010;75(17):1533-1539.

21. Spanos A, Harrell FE Jr, Durack DT. Differential diagnosis of acute meningitis. An analysis of the predictive value of initial observations. JAMA. 1989;262(19): 2700-2707.

22. van de Beek D, Drake JM, Tunkel AR. Nosocomial Bacterial Meningitis. N Engl J Med. 2010;362(2):146-154.

23. Rubin DB. Multiple Imputation for Nonresponse in Surveys. John Wiley \& Sons: 2004 Vol 81

24. Weisfelt M, Van De Beek D, Spanjaard L, Reitsma JB, De Gans J. Communityacquired bacterial meningitis in older people. J Am Geriatr Soc. 2006;54(10) 1500-1507.

25. Brouwer MC, Tunkel AR, van de Beek D. Epidemiology, diagnosis, and antimicrobia treatment of acute bacterial meningitis. Clin Microbiol Rev. 2010;23(3):467-492.

26. Gouveia EL, Reis JN, Flannery B, et al. Clinical outcome of pneumococcal meningitis during the emergence of pencillin-resistant Streptococcus pneumoniae: an observational study. BMC Infect Dis. 2011;11(1):323.

27. Petzold A, Hinds N, Murray NF, et al. CSF neurofilament levels: a potential prognostic marker in Guillain-Barré syndrome. Neurology. 2006;67(6):1071-1073.

28. Gagliardi D, Meneri M, Saccomanno D, Bresolin N, Comi GP, Corti S. Diagnostic and prognostic role of blood and cerebrospinal fluid and blood neurofilaments in amyotrophic lateral sclerosis: a review of the literature. Int J Mol Sci. 2019;20(17):4152.

29. Lu CH, Macdonald-Wallis C, Gray E, et al. Neurofilament light chain: a prognostic biomarker in amyotrophic lateral sclerosis. Neurology. 2015;84(22):2247-2257.

30. Fisse AL, Pitarokoili K, Leppert D, et al. Serum neurofilament light chain as outcome marker for intensive care unit patients. J Neurol. 2021; 268(4):1323-1329.

31. Preische O, Schultz SA, Apel A, et al. Serum neurofilament dynamics predicts neurodegeneration and clinical progression in presymptomatic Alzheimer's disease. Nat Med. 2019;25(2):277-283.

32. Meeter LHH, Vijverberg EG, Del Campo M, et al. Clinical value of neurofilament and phospho-tau/tau ratio in the frontotemporal dementia spectrum. Neurology. 2018; 90(14):e1231-e1239.

33. van Lieverloo GGA, Wieske L, Verhamme C, et al. Serum neurofilament light chain in chronic inflammatory demyelinating polyneuropathy. J Peripher Nerv Syst. 2019; 24(2):187-194

34. Barro C, Benkert P, Disanto G, et al. Serum neurofilament as a predictor of disease worsening and brain and spinal cord atrophy in multiple sclerosis. Brain. 2018;141(8): 2382-2391.

35. Kapoor R, Smith KE, Allegretta M, et al. Serum neurofilament light as a biomarker in progressive multiple sclerosis. Neurology. 2020;95(10):436-444

36. Wihersaari L, Ashton NJ, Reinikainen M, et al. Neurofilament light as an outcome predictor after cardiac arrest: a post hoc analysis of the COMACARE trial. Intensive Care Med. 2021;47(1):39-48.

37. Moseby-Knappe M, Mattsson N, Nielsen N, et al. Serum neurofilament light chain for prognosis of outcome after cardiac arrest. JAMA Neurol. 2019;76(1):64-71.

38. Weisfelt M, van de Beek D, Spanjaard L, Reitsma JB, de Gans J. A risk score for unfavorable outcome in adults with bacterial meningitis. Ann Neurol. 2008;63(1):90-97.

39. Bijlsma MW, Brouwer MC, Bossuyt PM, et al. Risk scores for outcome in bacterial meningitis: systematic review and external validation study. J Infect. 2016;73(5) 393-401.

40. Kester MI, Scheffer PG, Koel-Simmelink MJ, et al. Serial CSF sampling in Alzheimer's disease: specific versus non-specific markers. Neurobiol Aging. 2012;33(8):1591-1598. 


\section{Neurology \\ Neuroimmunology \& Neuroinflammation}

\section{CSF Neurofilament Light Chain Concentrations Predict Outcome in Bacterial Meningitis}

Nora Chekrouni, Thijs M. van Soest, Matthijs C. Brouwer, et al.

Neurol Neuroimmunol Neuroinflamm 2022;9;

DOI 10.1212/NXI.0000000000001123

This information is current as of December 13, 2021

\section{Updated Information \& Services}

References

Subspecialty Collections

Permissions \& Licensing

Reprints including high resolution figures, can be found at: http://nn.neurology.org/content/9/1/e1123.full.html

This article cites 39 articles, 4 of which you can access for free at: http://nn.neurology.org/content/9/1/e1123.full.html\#\#ref-list-1

This article, along with others on similar topics, appears in the following collection(s):

Bacterial infections

http://nn.neurology.org//cgi/collection/bacterial_infections

Meningitis

http://nn.neurology.org//cgi/collection/meningitis

Prognosis

http://nn.neurology.org//cgi/collection/prognosis

Information about reproducing this article in parts (figures,tables) or in its entirety can be found online at:

http://nn.neurology.org/misc/about.xhtml\#permissions

Information about ordering reprints can be found online:

http://nn.neurology.org/misc/addir.xhtml\#reprintsus

Neurol Neuroimmunol Neuroinflamm is an official journal of the American Academy of Neurology.

Published since April 2014, it is an open-access, online-only, continuous publication journal. Copyright

Copyright $\odot 2021$ The Author(s). Published by Wolters Kluwer Health, Inc. on behalf of the American

Academy of Neurology.. All rights reserved. Online ISSN: 2332-7812.

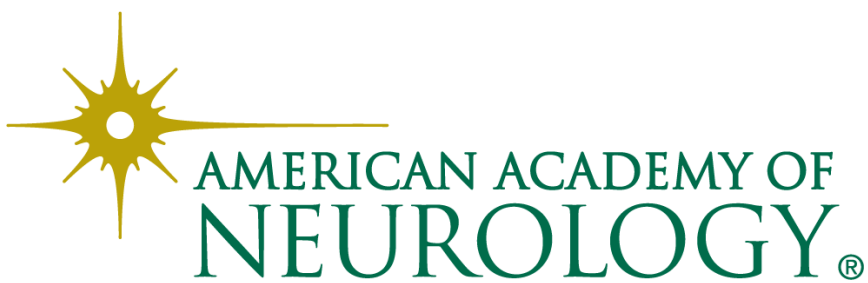

